\title{
SHARP BERNSTEIN INEQUALITIES USING CONVEX ANALYSIS TECHNIQUES
}

\section{G. Araújo, G. A. Muñoz-Fernández, D. L. Rodríguez-Vidanes And J. B. SEOANE-SEPÚlVEDA}

Abstract. In this paper we consider the space of polynomials of degree at most three in the real line endowed with the sup norm over the unit interval. We provide, explicitly, all the extreme points of the unit ball of this space. Using the previous geometrical description, we obtain the Bernstein function for the first and second derivative of the polynomials of degree at most 3 .

Mathematics subject classification (2010): 41A17, 26D05.

Keywords and phrases: Polynomial inequalities, Bernstein and Markov inequalities, extreme points.

\section{REFERENCES}

[1] G. Araújo, P. H. Enflo, G. A. Muñoz-Fernández, D. L. Rodríguez-Vidanes and J. B. SEOANE-SEPÚLVEDA, Quantitative and qualitative estimates on the norm of products of polynomials, Israel Journal of Mathematics (in press), DOI: 10.1007/s11856-020-1987-y.

[2] R. M. ARON AND M. KlimeK, Supremum norms for quadratic polynomials, Arch. Math. (Basel), 76, 1 (2001), 73-80.

[3] L. Bernal-González, G. A. Muñoz-Fernández, D. L. Rodríguez-Vidanes and J. B. SEOANE-SEPÚlVEDA, A complete study of the geometry of 2-homogeneous polynomials on circle sectors, Preprint (2019).

[4] S. BERNSTEIN, Sur L'ordre de la meilleure approximation des fonctions continues par des polynomes de degré donné, Memoires de l'Académie Royale de Belgique, 4, (1912), 1-103.

[5] Bernstein, S., Collected works: Vol. I. Constr. theory of functions (1905-1939). English translation., Atomic Energy Commission, Springfield, VA, 1958.

[6] P. R. BOAs, JR., Inequalities for the derivatives of polynomials, Math. Mag., 42, (1969), 165-174.

[7] Y. S. CHOI AND S. G. KIM, The unit ball of $\mathscr{P}\left({ }^{2} l_{2}^{2}\right)$, Arch. Math. (Basel), 71, 6 (1998), 472-480.

[8] Y. S. ChOI AND S. G. KIM, Smooth points of the unit ball of the space $\mathscr{P}\left({ }^{2} l_{1}\right)$, Results Math., 36, 1-2 (1999), 26-33.

[9] Y. S. ChOI AND S. G. KIM, Exposed points of the unit balls of the spaces $\mathscr{P}\left({ }^{2} l_{p}^{2}\right)(p=1,2, \infty)$, Indian J. Pure Appl. Math., 35, 1 (2004), 37-41.

[10] S. DineEn, Complex analysis on infinite-dimensional spaces, Springer-Verlag London, Ltd., Springer Monographs in Mathematics, London, 1999.

[11] R. Duffin And A. C. SchaefFer, Some properties of functions of exponential type, Bull. Amer. Math. Soc., 44, 4 (1938), 236-240.

[12] J. L. Gámez-Merino, G. A. Muñoz-Fernández V. M. SÁnchez and J. B. SeonneSEPÚLVEDA, Inequalities for polynomials on the unit square via the Krein-Milman theorem, J. Convex Anal., 20, 1 (2013), 125-142.

[13] B. C. GRECU, Geometry of homogeneous polynomials on two-dimensional real Hilbert spaces, J. Math. Anal. Appl., 293, 2 (2004), 578-588.

[14] B. C. GRECU, Extreme 2-homogeneous polynomials on Hilbert spaces, Quaest. Math., 25, 4 (2002), $421-435$.

[15] B. C. GReCU, Geometry of 2-homogeneous polynomials on $l_{p}$ spaces, $1<p<\infty$, J. Math. Anal. Appl., 273, 2 (2002), 262-282.

[16] B. C. GRECU, Smooth 2-homogeneous polynomials on Hilbert spaces, Arch. Math. (Basel), 76, 6 (2001), 445-454. 
[17] B. C. GReCU, Geometry of three-homogeneous polynomials on real Hilbert spaces, J. Math. Anal. Appl., 246, 1 (2000), 217-229.

[18] B. C. Grecu, G. A. Muñoz-Fernández and J. B. Seonne-Sepúlveda, The unit ball of the complex $\mathscr{P}\left({ }^{3} H\right)$, Math. Z., 263, 4 (2009), 775-785.

[19] B. C. Grecu, G. A. Muñoz-Fernández and J. B. Seoane-Sepúlveda, Unconditional constants and polynomial inequalities, J. Approx. Theory, 161, 2 (2009), 706-722.

[20] V. A. GusEV, Functionals of the derivatives of an algebraic polynomial and a theorem of V. A. Markov (Russian), Izv. Akad. Nauk SSSR Ser. Mat., 25, (1961), 367-384.

[21] A. G. KonHeIm AND T. J. RivLin, Extreme points of the unit ball in a space of real polynomials, Amer. Math. Monthly, 73, (1966), 505-507.

[22] A. MARKov, On a problem of D. I. Mendeleev (Russian), Zapiski Imp. Akad. Nauk, 62, (1889), 1-24.

[23] A. Markov, On a problem of D. I. Mendeleev, Electronic article to be downloaded from http://www.math.technion.ac.il/hat/papers.html.

[24] L. MILEV AND N. NAIDENOV, Indefinite extreme points of the unit ball in a polynomial space, Acta Sci. Math. (Szeged), 77, 3-4 (2011), 409-424.

[25] L. Milev And N. NAIDENOV, Strictly definite extreme points of the unit ball in a polynomial space, C. R. Acad. Bulgare Sci., 61, 11 (2008), 1393-1400.

[26] L. Milev And N. NAIDENOV, Semidefinite extreme points of the unit ball in a polynomial space, J. Math. Anal. Appl., 405, 2 (2013), 631-641.

[27] G. A. Muñoz-Fernández, D. Pellegrino, J. B. Seoane-Sepúlveda and A. Weber, Supremum norms for 2-homogeneous polynomials on circle sectors, J. Convex Anal., 21, 3 (2014), 745-764.

[28] G. A. MuÑoz-FernándeZ, S. Gy. RÉvÉSz AND J. B. SEOANE-SEPÚlvedA, Geometry of homogeneous polynomials on non symmetric convex bodies, Math. Scand., 105, 1 (2009), 147-160.

[29] G. A. MuÑOZ AND Y. SARANTOPOulos, Bernstein and Markov-type inequalities for polynomials on real Banach spaces, Math. Proc. Cambridge Philos. Soc., 133, 3 (2002), 515-530.

[30] G. A. MuÑoz-FernándeZ, Y. Sarantopoulos and J. B Seoane-Sepúlveda, An application of the Krein-Milman theorem to Bernstein and Markov inequalities, J. Convex Anal., 15, 2 (2008), 299-312.

[31] G. A. Muñoz-Fernández And J. B. SeoAne-Sepúlveda, Geometry of Banach spaces of trinomials, J. Math. Anal. Appl., 340, 2 (2008), 1069-1087.

[32] S. Neuwirth, The maximum modulus of a trigonometric trinomial, J. Anal. Math., 104, (2008), 371-396.

[33] E. V. VoronovsKaJA, The method of functionals as applied to problems of Zolotarev-Přeborski type (Russian), Dokl. Akad. Nauk SSSR, 194, (1970), 20-23. 